\title{
Learning English Vocabulary in a Mobile Assisted Language Learning (MALL) Environment: A Sociocultural Study of Migrant Women
}

\author{
Kham Sila Ahmad, Fay Sudweeks, and Jocelyn Armarego \\ School of Engineering and Information Technology, \\ Murdoch University, Murdoch, WA, Australia
}

\section{7@student.murdoch.edu.au Sudweeks@murdoch.edu.au J.Armarego@murdoch.edu.au}

\begin{abstract}
This paper reports on a case study of a group of six non-native English speaking migrant women's experiences learning English vocabulary in a mobile assisted language learning (MALL) environment at a small community centre in Western Australia. A sociocultural approach to learning vocabulary was adopted in designing the MALL lessons that the women undertook. The women provided demographic information, responded to questions in a pre-MALL semistructured interview, attended the MALL lessons, and completed a post-MALL semi-structured interview. This study explores the sociocultural factors that affect migrant women's language learning in general, and vocabulary in particular. The women's responses to MALL lessons and using the tablet reveal a positive effect in their vocabulary learning.
\end{abstract}

Keywords: MALL, sociocultural approach, migrant women, vocabulary

\section{Introduction}

A large volume of research has been published in the Mobile Assisted Language Learning (MALL) field over the past twenty years following the rapid development and advancement in mobile technologies (Burston, 2014; Stockwell \& Hubbard, 2013; Viberg \& Gronlund, 2012). As part of computer-assisted language learning (CALL), MALL utilises mobile devices such as smartphones, tablets, and iPods to support language learning (Chuang, 2009; Ozdogan, Basoglu, \& Ercetin, 2012; Stockwell \& Hubbard, 2013; Tai, 2012). Research has demonstrated the feasibility of MALL for language learning; however, the majority of MALL learning takes place with-

Material published as part of this publication, either on-line or in print, is copyrighted by the Informing Science Institute. Permission to make digital or paper copy of part or all of these works for personal or classroom use is granted without fee provided that the copies are not made or distributed for profit or commercial advantage AND that copies 1) bear this notice in full and 2) give the full citation on the first page. It is permissible to abstract these works so long as credit is given. To copy in all other cases or to republish or to post on a server or to redistribute to lists requires specific permission and payment of a fee. Contact Publisher@InformingScience.org to request redistribution permission. in academic contexts, such as schools and universities where participants are literate in their native language, familiar with English, and are in a formal and structured environment. The research reported in this paper is part of a larger study investigating the learning experiences of migrant women in a nonacademic context, who have lived in Australia between two and seven years, are literate in their native language, but 
are struggling with English. In Australia, proficiency of the English language is essential for general social interaction, furthering education and employment (ASIB, 2012; Bimrose \& McNair, 2011; Colic-Peisker \& Tilbury, 2007; Fozdar \& Hartley, 2012; Smolicz \& Secombe, 2003).

This study focuses on the sociocultural factors that affect migrant women's language learning in general and vocabulary acquisition in particular. This study specifically addresses vocabulary acquisition as it is a branch of language that is important for second language oral proficiency (J. Ahmad, 2011; Choo, Lin, \& Pandian, 2012; Coady \& Huckin, 1997). Vocabulary acquisition, centering on the speaking and listening branch of language development, is seen as useful and beneficial for migrant women to develop general English proficiency (K. S. Ahmad, Armarego, \& Sudweeks, 2013). The approach to learning vocabulary adopted in this study is supported by Halliday's (2004) and Vygotsky (1978)'s sociocultural theory.

\section{Background}

For this study, the term 'migrant women' refers to women who enter Australia under the family reunion program or for humanitarian reasons. Typically, the purpose of migration is to build a new and better life for families; however, the causes of migration can be "personal and voluntary" or "forced" due to political turmoil, threats to their lives, violence, famine, or war (Kunz, 1973; UN, 2013; UNHCR, 2011; Ward, Bochner, \& Furnham, 2001). Settlement into a new life includes having to learn and adapt to a new culture, dealing with emotional and psychological issues, dealing with sociocultural and socioeconomic challenges, and learning English as a new language (OMI, 2012). The lack of English language proficiency is one of the common barriers for migrants' settlement in Australia (Coates \& Carr, 2005; Colic-Peisker \& Tilbury, 2007; Fozdar \& Hartley, 2012; Migliorino, 2011). For women, this barrier cannot be overcome as quickly as for men. To some extent, pressures of family duties, staying at home and engaging in fulltime care of families, leads to isolation from the broader community for several years. As a consequence, finding employment can be a challenging and overwhelming experience. Personal and sociocultural factors are the important influences in the lives of these women (AMES, 2011; ECCV, 2009; McMichael \& Manderson, 2004). It has been observed (K. S. Ahmad et al., 2013; RCOA, 2010) that, in terms of these women learning English, the programs offered by local and non-profit community-based centres are the best alternative to the formal government-funded programs. Even though the former is non-accredited and short term, it is the kind of learning opportunity and space that suits their needs for a friendly and non-rigid learning environment that allows them to learn and practise basic speaking and conversational skills.

The case study for this research is a community centre in Western Australia, which is a non-profit organization providing community access to both formal and informal learning opportunities as well as community services and referrals to other agencies. The first author of this paper is a facilitator of an English program for adult migrants at the centre. The objective of the English program is to provide a learning space for people to meet and socialise with others who also want to practise spoken English. Their main motivation for attending the program is to learn, practise, and improve their basic conversational and other language skills. The program is open to both men and women; however, the majority of participants are women.

Integrating MALL into this particular community English program includes using a mobile device, that is, a tablet as a learning tool. This inclusion of a mobile device enriches the learning experience because the features of these devices can enhance the delivery of learning materials. As suggested by Klopfer, Squire, and Jenkins (2002), these features include connectivity, context sensitivity, individuality, portability, and social interactivity. Regardless of the learners' location, they can access learning materials and activities spontaneously. The learner and the mobile devices are both portable as the learner can access and be connected online. The learner has a choice whether to use the mobile device individually and personalize his/her learning to or learn collabo- 
ratively with other learners (Cavus \& Ibrahim, 2009). MALL can also be used in a blended setting where in-classroom instruction is combined with out-of-class instruction, thus maximising the benefits of in-class, face-to-face, and online learning (Tai, 2012). In the context of this case study, the integration of MALL also helps develop digital literacy skills among these women. This is because, by learning how to use a mobile device, the women can use it for other learning such as other life skills. Familiarity with the mobile devices facilitates access to useful websites and networks (social, government, or career), thus reducing isolation in their lives. Being proficient in English and being digitally proficient also increases the chances of being included (Migliorino, 2011) into the highly digital literate Australian culture and society (Thomson \& De Bortoli, 2012).

\section{Learning English and MALL through the Lens of Sociocultural Theory}

The approach to learning vocabulary adopted in this study is supported by the sociocultural theory of Halliday (2004) and Vygotsky (1978). Both theorists emphasise that language learning is primarily a social activity and the learners should be involved in negotiating and make meaning in authentic social and cultural activities. Following Grabinger, Aplin, and Ponnappa-Brenner's (2007) idea of social cultural learning environment, learners should become familiar with the social norms and discourse of the target language. Learners should also be given the opportunity to apply them in an authentic way. Vocabulary learning is not only about acquiring the meaning and knowledge of the words or phrases but also being able to use them for meaningful communication.

According to O'Neill and Gish (2008), in learning a second language, successful cross-cultural understanding and intercultural literacy for both learners and their teacher/facilitator is required where learning experiences should take place in a variety of sociocultural settings. This can be achieved through a process of continual "constructing, interpreting, and modifying their representations of reality based upon experience and negotiation of meaning with others" (Grabinger et al., 2007, p. 2). According to Burgoyne and Hull (2007), this continual process allows individuals to become members of the group in which they play a part by assuming the emerging identity that is associated with the language that they are learning. In addition, the principle of participation fortifies the viewing of learning as a collaborative process and as a way of transforming knowledge making. This allows participants to shape the process and products of knowledge (O'Byrne, 2003). Through interactions, individuals engage with each other and they construct knowledge through their social and cultural practices. Martin and Rose (2005) emphasise that coconstruction of knowledge makes new learning possible within the continuing practice and social environment. Billet (1998) posits that, without continual participation in social practice, knowledge will not be accessible, thus learning outcomes are likely to be inhibited. Therefore, successful communication in English requires participation in a social practice and involves all traits of an individual's sense of social identity and social resources. On this basis, a sociocultural approach is adopted in this case study in designing the MALL integrated vocabulary lessons for the participants.

In designing vocabulary lessons incorporating MALL concepts for adult learners, consideration should be given to principles of andragogy (Knowles, 1984) that are widely used for developing adult learning curricula. These principles are based on five crucial suppositions about adult learners' characteristics that differ from children's pedagogy: self-directed; equipped with experience; ready to learn; oriented toward being problem-centred rather than subject-centred; and motivated (Smith, 2002). For adult learners, learning English as a second language in general, and English vocabulary specifically, is influenced by factors such as level of education in native language (L1), culture, past experiences, age, and opportunities to speak English (Allender, 1998; 
Hewagodage \& O'Neill, 2010). There is also the need to consider previous psychological and emotional concerns, such as trauma, settlement, and family priorities or confidence and motivational issues (Fozdar \& Hartley, 2012). There may also be different understandings among cultures about teaching methodology, teacher-learner rapport, and modern pedagogical practices. In addition, the idea of self-assessment, critical discussion, and the physical climate of the learnercentred learning environment may be alienating for some. Thus, the pedagogical approach adopted for adult migrants' English language learning in general is crucial for language learning success.

Among studies that show the feasibility of MALL in language acquisition within formal education settings are those by Alemi, Sarab, and Lari (2012), Cavus and Ibrahim (2009), Chuang (2009), Gu, Gu, and Laffey (2011), and Thornton and Houser (2005). Some of the factors central to the MALL environment are the characteristics of the mobile devices used. For example, allowing learners to access learning materials without time and space constraints is effective for delivering language learning materials to learners (Thornton \& Houser, 2005). In addition, mobile devices are more cost efficient compared to desktop or laptop machines, thus they are more affordable to language learners (Wu et al., 2012). A review of the literature by K. S. Ahmad et al. (2013) suggests that these factors of MALL are potentially beneficial to English learners such as migrant women. Further, the suitable area of English language that these learners should focus on is vocabulary. According to J. Ahmad (2011), vocabulary learning is a crucial process for language learners to acquire proficiency and competence in a language. Qian (1999) states that vocabulary knowledge refers to the size as well as the depth of vocabulary, which includes knowledge about the contexts in which the word is used, the frequency with which it is used, its morphology, its syntax, whether it has multiple meanings, pronunciations and spellings, and how the word combines with other words. A wealth of words or a word bank facilitates fluent and effective speaking and writing, whilst other skills (listening, reading, speaking, and writing) are enriched and integrated as well. The greater the number of words in a learner's word bank, the more instruments they have with which to put a point on their own ideas, and dissect and examine those of others (J. Ahmad, 2011; Elgort, 2011). As such, knowledge of vocabulary is valuable and useful for a language learner.

Krashen and Terrell (2000) claim that comprehension is not possible without vocabulary. The more vocabulary is mastered, the better one's comprehension and thus more acquisition of language occurs. Kenny (2011) also suggests that, in order for humans to acquire other words and syntax, they will have to initially acquire vocabulary. It is beneficial for language learners to have vocabulary knowledge and be able to use this knowledge in their day-to-day lives. Having a range of vocabulary and feeling confident in using it leads to the ability to be clear when sharing ideas and thoughts, or simply when making conversation (J. Ahmad, 2011; Elgort, 2011; Nation \& Newton, 2009). This increases the likelihood that other people will understand what is expressed. A diverse vocabulary allows learners to connect with a broader variety of people (Lightbown \& Spada, 1993; Mishra, 2010). For example, knowing some business terms assists in not being taken advantage of. Also, vocabulary is essential for comprehending reading materials (Krashen \& Terrell, 2000; Lightbown \& Spada, 1993). Comprehension of what is being read is hindered due to unfamiliar words that tend to become little holes in the text. Vocabulary also assists learners in becoming more informed and involved. For example, learners will have a better understanding of news and currents events if they understand politics and geography. Learners will also be able to grasp ideas and think more rationally and incisively.

\section{Case Study}

The case study is a small community centre that is a non-profit organization in a suburb in Western Australia. The centre provides community services and learning programs to the surrounding 
community members. One of its programs is learning conversational English, which was started in 2001. The first author of this paper has been the coordinator and facilitator of this program for the past two years. The main objective of this program is to provide a non-formal learning space for people who want to practise basic conversational and survival English, whilst meeting and socializing. The program is free of charge, offers a learning atmosphere that is relaxed, supportive, non-threatening and provides a somewhat level playing field for learning. A crèche facility is also provided for mothers with small children. This program is open once a week, for two hours, during public school terms.

Attendance in the program is not compulsory. As such, attendance is irregular, contingent upon participants' availability and convenience. About 40 participants enroll in the program each term with an average attendance of 12 to 15 per session. Some participants have been regulars for many years, though they do not come to every session. The program receives new participants almost every term, but it is never known whether they will return in successive sessions. Although the program is open to both men and women, it has been observed that women attend this program as a way to be able to get out of their house. Thus, in addition to learning English, the program reduces their isolation and allows them to interact, engage, and socialise with other women.

The sessions are meant to be non-formal and non-academic, as opposed to formal and structured English classes. The physical layout of a session includes two large tables where 12 participants can sit around each table. Upon agreement with the centre's management, the facilitator plans topics to be included for the 10-session term. Activities may include the following: introducing vocabularies and phrases using pictures and realia, followed by making sentences using learnt vocabularies; eliciting discussions based on topics; role playing and listening to a CD (where participants listen to short dialogues by native English speakers, followed by a discussion); and any current issues or topics that participants want to share with their peers. The whiteboard is used to write words, phrases, or draw pictures for illustration. Participants who can read and write in the Roman alphabet are able to copy the words on the board fairly quickly. Participants who are able to read and write in their native language usually copy the words from the board and write notes in their language. Other participants who struggle or are unable to read and write use their visual and listening ability and their memory.

The sessions are not fast paced, as sometimes more time is needed to describe or explain words and concepts, and sometimes participants help and translate for each other. Some repetition drills are used to help participants become familiar with new vocabularies and phrases. It is observed that new participants who speak very little English usually only speak when spoken to during their first session. In subsequent sessions, they seem more comfortable and more proactive in the conversations. The author observes that both new and regular participants face the same challenges when they engage in conversations; mainly, they feel unsure and have limited vocabulary which impedes fluency. For example, when sharing their stories about what they did during the weekend, their facial expression and their bodily gestures show that is takes effort to form the sentences in their minds and courage to utter and speak up in front of other people. In addition to this, there are unintentional errors and/or prompts that the participants usually make, such as missing or incorrect uses of words in sentences, incorrect pronunciation, interweaving of L1 words, and pausing midconversation to think of the word to use or asking/confirming with a friend or the author that they are saying things correctly. Nonetheless, they are receptive when their mistakes or errors are being corrected. These issues do not hinder them from engaging in conversations, and they understand that the purpose of the program is for them to practice conversing in English.

\section{Methodology}

This study explores the experiences of a group of six non-native English speaking migrant women in learning English vocabulary in a MALL environment through the perspective of sociocul- 
tural theory. They attend a non-formal English program at their local community centre. The program involves two-hour non-formal conversational sessions each week for non-English speakers. On average, fifteen people attend the program; however, only six women were selected for this study as they were regulars and attended a majority of the MALL-integrated vocabulary lessons (from this point onwards to be known as MALL lessons) that was conducted. Ten tablets were supplied by the community centre for the study. The tablet was introduced into the program in a gradual manner, so as to avoid feelings of intrusiveness and intimidation among the attendees. An important criterion for the introduction of the tablets was to maintain the naturalistic and nonformal feel to the program as much as possible. The investigation was conducted using the community centre as a case study (Creswell, 2012; Leedy \& Ormrod, 2005; Yin, 2011). The six women provided demographic information and responded to questions in a pre-MALL semistructured interview, attended MALL lessons, and completed a post-MALL semi-structured interview. Informed by the literature review, the research questions are as follows:

RQ1: What sociocultural factors affect migrant women's vocabulary acquisition?

RQ2: What MALL factors affect migrant women's vocabulary acquisition?

\section{Pre-MALL and Post-MALL Interviews}

Semi-structured interviews were conducted before participants attended the MALL lessons (preMALL) and after they attended the MALL lessons (post-MALL). The pre-MALL interview collected data on demographics about participants' migration histories, country of origin, the main language and other languages they speak, level of education, and familiarity with computer and mobile devices. These were followed by questions regarding their perceptions of their own English ability and their view of the importance of English. The purpose of the post-MALL interviews was to learn of participants' experience learning English vocabulary in a MALL environment and of using the tablet.

Data was collected using semi-structured interviews, as informed by the work of Creswell (2012) and Yin (2011). Semi-structured interviews have an overall structured framework but they allow for greater flexibility. The interviewer remains in control of the direction of the interview, though with some leeway. For example, for this study, the order of questions was changed and some questions were probed further for more extensive follow-up of responses. This created richer interactions and more personalised responses (McDonough \& McDonough, 1997). In addition, the established rapport between the interviewer and the participants encouraged them to speak freely (Miralles-Lombardo, Miralles, \& Golding, 2008). In some of the interviews, the interviewer had interpreter help from other participants, thus allowing participants to express their views more deeply and freely in their native language. These factors elicited more valid responses from participants (Burns, 1994; McDonough \& McDonough, 1997). The interviews were audio-recorded then transcribed for analysis.

\section{MALL Lessons}

In designing the MALL lessons, the author had to consider the timeframe allowable for her to have access to the participants who were also part of the larger group who attended the English program. The author was permitted by the community centre to conduct research at their premises and use the same two-hour time block that is used for the regular conversational English program. The author also had to retain the similar non-formal setup of the regular English program while conducting the MALL lessons.

The tablets were introduced gradually to maintain the naturalistic and non-formal feel to the program while avoiding feelings of intrusiveness, intimidation and fear among the attendees. The majority of the program attendees are of low level English literacy; some struggle to read the words or texts on the tablet, while some were unable to read at all, let alone use the tablet and 
navigate the apps on the tablet. The groupings of attendees were then arranged in such a way that a higher literate person was partnered with a lower literate person. This allowed attendees to socially interact, engage, and work together in co-constructing meaning and knowledge with each other.

The topics selected for the MALL lessons considered the principles of andragogy (Knowles, 1984), the natural approach of language learning (Krashen \& Terrell, 2000), and the sociocultural instructional design (Grabinger et al., 2007; Halliday, 2004; Vygotsky, 1978). Combined, the vocabulary lessons for this study exposed participants to a variety of everyday functional and conversational language use, and focused on:

- language learning rather than the grammar and technicality of language;

- seeking fluency rather than accuracy, thus direct error correction and pronunciation work is not necessary at early stages;

- treating vocabulary as an essential component of learning English rather than grammar because extensive vocabulary knowledge permits fluency in communication;

- learning vocabularies that are essential to the learners' needs, strengths, weaknesses, and aspirations, for example, learning the phrases that are commonly used to ask permission politely or phrases used to describe people's facial features; and

- building listening and speaking skills.

Material for the MALL lessons were sourced from English as a Second Language (ESL) textbooks, ESL mobile apps, and ESL websites. Table 1 shows a sample of categories of everyday conversational language developed as a mobile app for the beginner level ESL adult learner. This app is called ThinkEnglish! and is developed and used by the Australian Migrant English Services in New South Wales for their adult migrant students in government-funded English programs. In each category a learner can watch and listen to conversations, practice vocabulary by matching the words with pictures while listening to word pronunciation, and practice speaking in an interactive medium with an audio recording facility.

Table 1: The categories of situations for everyday conversational language on the ThinkEnglish! app (AMES, 2011)

\begin{tabular}{|l|l|}
\hline \multicolumn{1}{|c|}{ Category } & \multicolumn{1}{c|}{ Sample Situations } \\
\hline At the shops & At the post office, at the chemist, at the library \\
\hline Daily life & What's the weather like, talking to neighbours \\
\hline People and places & Describing people, describing a city and country \\
\hline Messages & What's the matter, taking messages, leaving a message \\
\hline My news, in the news & The first day, a news story, celebrations \\
\hline
\end{tabular}

The following is a sample of how a MALL lesson on the topic of Describing People is conducted.

\section{Step 1}

Pictures were used to pre-teach vocabulary (words/phrases) such as "wears glasses", "beard and moustache", "spiky hair', "blonde hair", "tall and short", and "young" (Figure 1). The purpose of pre-teaching is for learners to understand the meaning and become familiar with the vocabulary so that it would be easier when encountering more complex sentences or texts. Each picture is of an A4 size. One picture was displayed on the board and discussion was elicited from the attendees based on this picture. With a partner, the attendees made sentences using the keyword/phrase and shared their sentences with the whole group. To encourage conversation, follow- 
up questions were asked from the sentence that was created and the attendees would try to compose follow-up sentences/answers. This process was repeated for the other pictures.

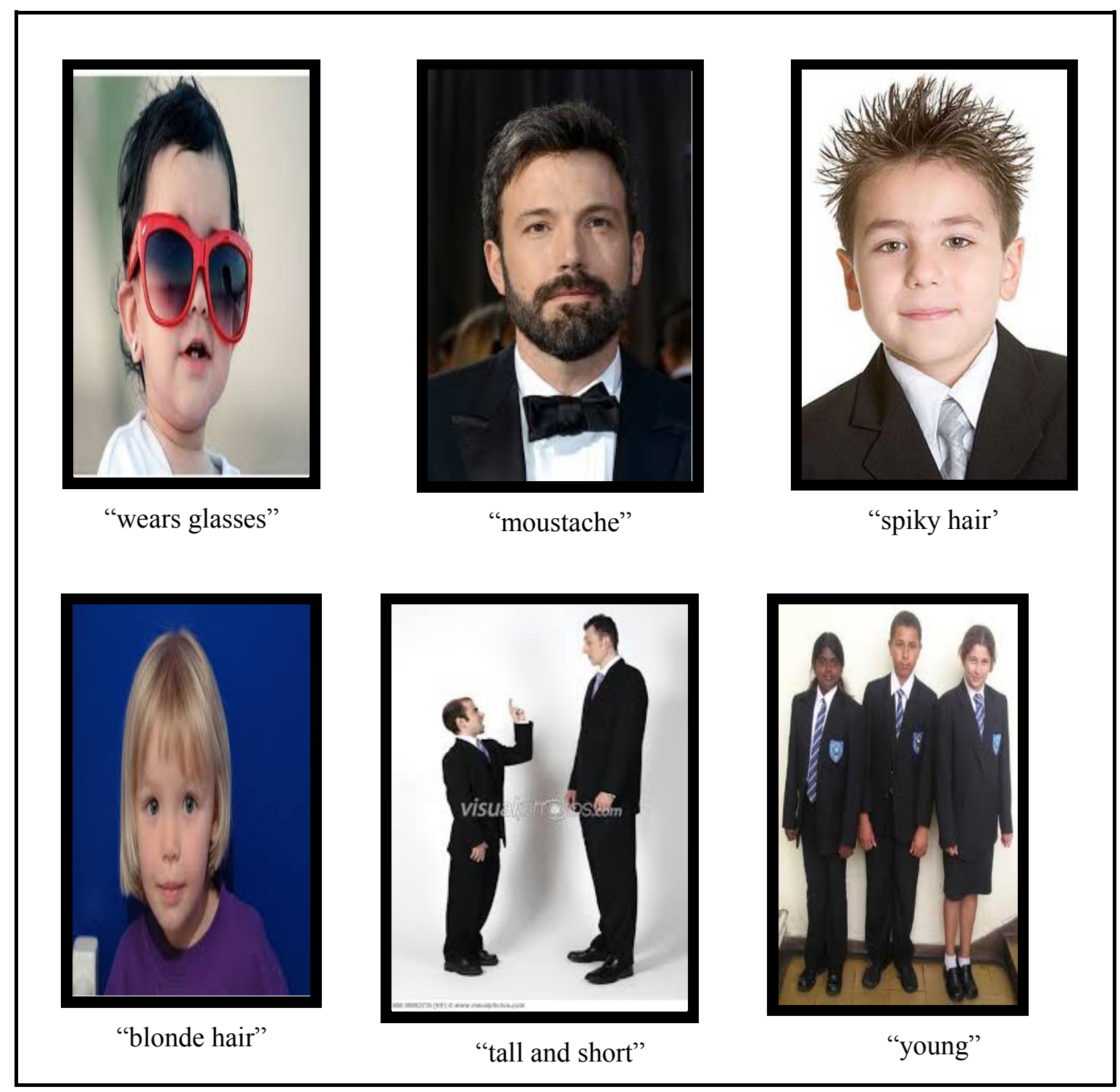

Figure 1: Pictures used for pre-teaching vocabulary

\section{Step 2}

This step is when drilling is used to help attendees practice fluency and become familiar with how the words and phrases are used. With all six pictures on the whiteboard, the following corresponding sentences are drilled:
a) "She wears glasses"
b) "He has a beard and a moustache"
c) "He's got spiky hair"
d) "She's got blonde hair"
e) "He's tall"
f) "He's short"
g) "They're young" 


\section{Step 3}

This is when each attendee was given a tablet to work with and paired with another attendee. The ThinkEnglish! app was downloaded on all 10 tablets before the start of the lesson, and it was ensured that the tablets were fully charged. The ThinkEnglish! app was then pre-set as the start page when the tablet was switched on by the learner. Figure 2(a) and Figure 3(a) are samples of the user interfaces on the tablet that the attendees of the MALL lessons were presented with to work on. Figure 2(b) and Figure 3(b) show the finished exercises that the attendees completed.

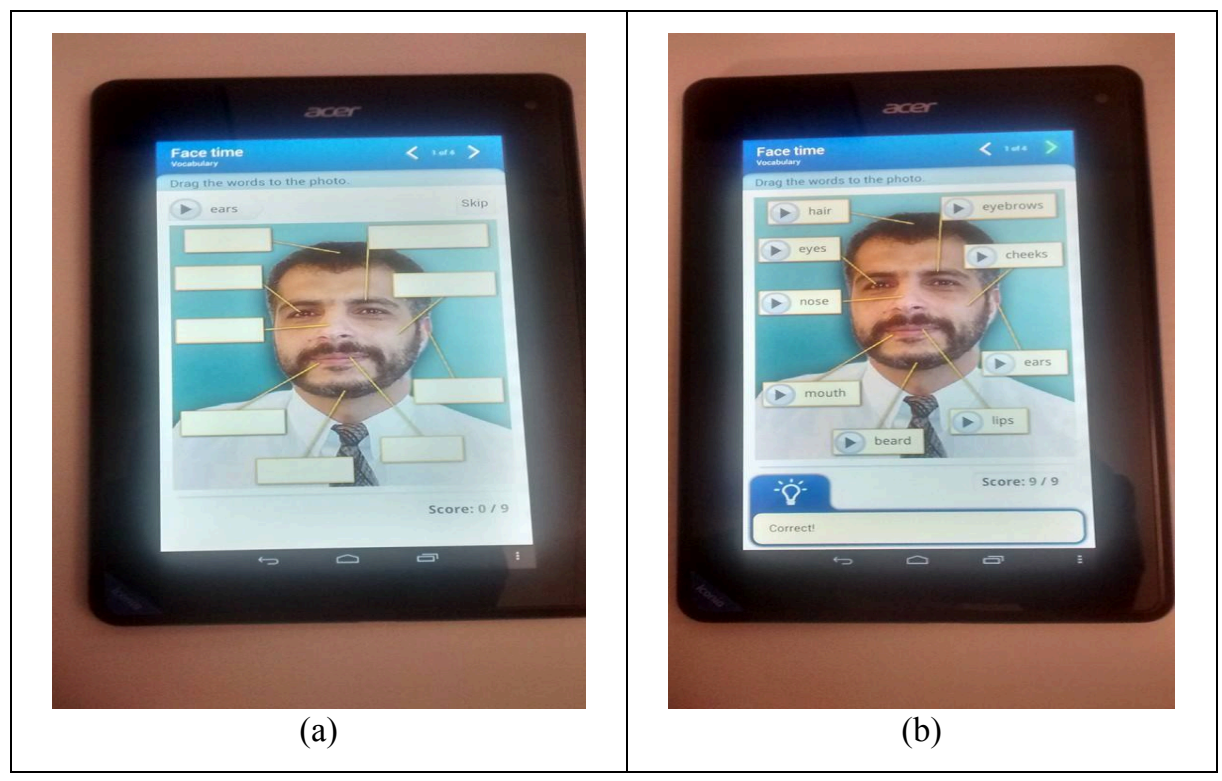

Figure 2: Sample of an interface of the app on the tablet used in this study as vocabulary exercise I

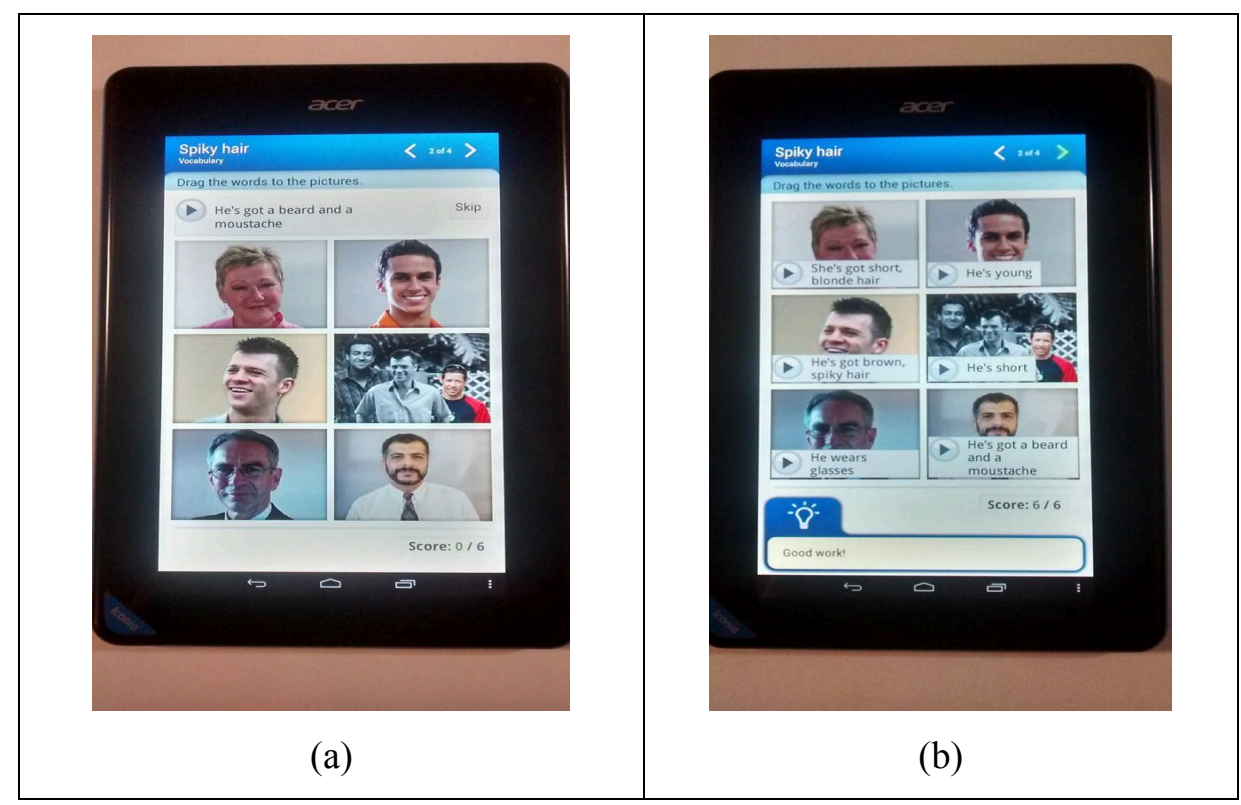

Figure 3: Sample of an interface of the app on the tablet used in this study as vocabulary exercise II 
Tapping on the play button lets one listen to the audio of the names of the facial item (Figure 2(a)). Attendees who struggle with reading can just tap the play button and listen to the audio, and try to recognise the word and what it means. By pressing the same button, the word can be dragged and placed in the correct box (Figure 2b). When the exercise is completed, as in Figure 2(b), one can tap on any of the play button to listen to the audio again. The exercise can be refreshed and repeated as many times as needed.

\section{Results}

\section{Demographic Information}

The six non-native English speaking migrant women participating in this study were selected using purposive sampling identified through the English conversational program from the case study site. They are aged between 29 to 51 years old. They have lived in Australia between 2 to 7 years. They are all literate in their native language and have completed high schools. They identified themselves as needing to improve their speaking skills to a level of English proficiency that allowed them to communicate comfortably to the wider native Australian English speakers. They also identified themselves as housewives with children going to school. Data were also collected about their country of origin, the first, second, and third language they spoke, and their level of literacy. Table 2 summarises this data.

Table 2: Demographic data

\begin{tabular}{|c|c|c|c|c|c|c|}
\hline \multirow{2}{*}{$\begin{array}{c}\text { Pseu- } \\
\text { donym }\end{array}$} & \multicolumn{3}{|c|}{ Migration to Australia } & \multicolumn{3}{|c|}{ Everyday Language Use (L1,L2,L3) } \\
\hline & Age & $\begin{array}{l}\text { Country of } \\
\text { origin }\end{array}$ & $\begin{array}{l}\text { Number of } \\
\text { years living } \\
\text { in Australia }\end{array}$ & $\begin{array}{l}\text { L1; } \\
\text { Script; } \\
{ }^{1} \text { Reading fluency; } \\
{ }^{2} \text { Writing fluency }\end{array}$ & $\begin{array}{l}\text { L2; } \\
\text { Script; } \\
{ }^{1} \text { Reading fluency; } \\
{ }^{2} \text { Writing fluency }\end{array}$ & $\begin{array}{l}\text { L3; } \\
\text { Script; } \\
{ }^{1} \text { Reading fluency; } \\
{ }^{2} \text { Writing fluency }\end{array}$ \\
\hline SURI & 29 & Indonesia & 2 & $\begin{array}{l}\text { Indonesian } \\
\text { Roman Alphabet } \\
\text { High } \\
\text { High }\end{array}$ & $\begin{array}{l}\text { English } \\
\text { Roman Alphabet } \\
\text { Low } \\
\text { Low }\end{array}$ & \\
\hline RINA & 33 & Indonesia & 2 & $\begin{array}{l}\text { Indonesian } \\
\text { Roman Alphabet } \\
\text { High } \\
\text { High }\end{array}$ & $\begin{array}{l}\text { English } \\
\text { Roman Alphabet } \\
\text { Low } \\
\text { High }\end{array}$ & $\begin{array}{l}\text { Rohingya } \\
\text { Arabic } \\
\text { Very Low } \\
\text { Very Low } \\
\end{array}$ \\
\hline LIDDY & 43 & China & 7 & $\begin{array}{l}\text { Mandarin } \\
\text { Logographic } \\
\text { High } \\
\text { High }\end{array}$ & $\begin{array}{l}\text { Cantonese } \\
\text { Logographic } \\
\text { High } \\
\text { High } \\
\end{array}$ & $\begin{array}{l}\text { English } \\
\text { Roman Alphabet } \\
\text { Average } \\
\text { Average }\end{array}$ \\
\hline ALLY & 38 & China & 2 & $\begin{array}{l}\text { Mandarin } \\
\text { Logographic } \\
\text { High } \\
\text { High }\end{array}$ & $\begin{array}{l}\text { Cantonese } \\
\text { Logographic } \\
\text { High } \\
\text { High } \\
\end{array}$ & $\begin{array}{l}\text { English } \\
\text { Roman Alphabet } \\
\text { Very Low } \\
\text { Low }\end{array}$ \\
\hline KEY & 51 & Malaysia & 2 & $\begin{array}{l}\text { Mandarin } \\
\text { Logographic } \\
\text { High } \\
\text { High }\end{array}$ & $\begin{array}{l}\text { Malay } \\
\text { Roman Alphabet } \\
\text { Average } \\
\text { Average }\end{array}$ & $\begin{array}{l}\text { English } \\
\text { Roman Alphabet } \\
\text { Low } \\
\text { Average }\end{array}$ \\
\hline ROSE & 44 & Congo & 7 & $\begin{array}{l}\text { Lingala } \\
\text { Extended Roman/Latin } \\
\text { Average } \\
\text { Average }\end{array}$ & $\begin{array}{l}\text { French } \\
\text { Roman Alphabet } \\
\text { High } \\
\text { High }\end{array}$ & $\begin{array}{l}\text { English } \\
\text { Roman Alphabet } \\
\text { Low } \\
\text { Low }\end{array}$ \\
\hline
\end{tabular}

${ }^{1}$ Reading fluency: Very high $=$ able to read and comprehend complex texts (e.g. academic texts); High $=$ able to read and comprehend non-complex texts; Average = able to read non-complex texts; Low $=$ Struggle to read in general; Very low $=$ not able to read at all.

${ }^{2}$ Writing fluency: Very high $=$ able to write (produce) complex texts; High = Able to write (produce) non-complex texts; Average $=$ Able to copy non-complex texts; Low $=$ Able to copy simple words and sentences; Very low $=$ not able to write. 


\section{Sociocultural Influences on Learning}

The following provides other participant background details important to gaining an understanding of how sociocultural factors affect the women's lives and their reactions to learning English in general.

\section{SURI (Indonesia)}

Suri is a married Muslim. She and her husband and three children came to Australia as refugees. Her husband is Rohingya Burmese. Suri still experiences migration trauma due to spending ten days travelling by boat. Currently they are under a refugee protection visa while waiting for their permanent residency to be approved. Suri is restricted socially due to her cultural and religious background. She rarely mixes with English-speaking people in the society. She only mixes with other multicultural community members when she attends programs organized by the community centre.

Suri completed primary and high school in Indonesia. She learned basic English in both schools. The medium of reading and writing was Roman alphabet. However, she writes slowly now because of lack of practice and she is unsure of the spelling. Suri values the importance of being proficient in English because of living in Australia but she is still quite embarrassed about speaking English. She always worries about making mistakes. She also finds it hard to understand native Australian speakers when they speak.

\section{RINA (Indonesia)}

Rina is a married Muslim. She and her husband and their two children came to Australia as refugees. Her husband is Rohingya Burmese. Rina was pregnant with her third child when they travelled by boat for ten days to Australia. Rina would like to work but her refugee protection visa status prohibits her to do so. They have been waiting for their permanent residency to be approved for one and a half years. Rina completed primary and high school in Indonesia. Basic English was taught in both schools. The Roman alphabet was used as the medium of reading and writing. Rina has no problem writing/copying words from the board.

Rina can speak basic English very confidently. She is not embarrassed to speak English and make mistakes. Rina takes her two-year old daughter and her three year old son to a playgroup near her housing complex. At other times, Rina mostly stays at home caring for her children. Rina is currently pregnant with her fourth child. Rina finds it hard to understand the Australian accent. This is one of the reasons she feels very strongly that she needs to be good at speaking English, so that she can communicate better with her son's teachers, to other Australian native speakers and people at the government office. She would also prefer to not have to rely on her 13 year old son to interpret for her.

\section{LIDDY (China)}

Liddy lived in New South Wales and Victoria before moving to Western Australia. She has 17 year old twin boys. She has work experience in a meat factory in Victoria. That work experience gave her exposure to English. Liddy has developed proficiency in basic English due to living in Australia for seven years. However, she feels she can do better and that she needs to improve her reading and writing to prepare her for other courses that will enable her to find a better job. Liddy completed primary and high school in China. Non-alphabetic Chinese characters or logographic was used as the medium of reading and writing. She learnt basic English and Roman alphabet writing.

Liddy is eager to start formal learning but at the same time she does not feel ready because she thinks she needs to improve her speaking, reading, writing, and listening skills. She thinks the listening skill is important because she still finds it hard to understand the Australian accent and 
when speaking with native English speakers. Liddy plans to take aged-care certificates when she is ready.

\section{ALLY (China)}

Ally married her Australian husband two years ago and moved to Australia. Her husband is a proficient Mandarin speaker who spent three years learning the language. Ally and her husband speak more Mandarin at home than English, which is her motivation for attending the conversational English program at the community centre. Ally is not eligible for the government-funded English program due to her visa status. Ally spoke only a few words of English when she first joined the conversational English program. Ally has slowly increased her word bank, which allows her to use a greater variety of words when communicating. Ally also seems to be more confident in speaking English.

Ally completed primary and high school in China where non-alphabetic Chinese characters or logographics was used as the medium of reading and writing. She did not learn English and Roman alphabet reading and writing at all. This causes Ally to not have confidence in reading and writing in English. Ally struggles when reading English words and short sentences, but she has no problem writing (copying) words and short sentences.

Ally finds it hard speaking to Australian native English speakers because of the Australian accent. Ally wants to improve her English so that she can communicate with her husband's family and be able to do courses and to find jobs. She feels that she needs to prepare herself by improving all four English skills (reading, writing, speaking, and listening). Ally plans to work in the marketing sector when she is ready and after her permanent residency visa is approved.

\section{KEY (Malaysia)}

Key is a Malaysian Chinese who married her husband two years ago and moved to Western Australia. Her husband is a Malaysian Chinese who is now an Australian citizen. Key is still adjusting to a new life in Australia. Key finds it hard to understand Australian native speakers when they speak, thus she relies a lot on her husband or his son to interpret for her.

In Malaysia, Key went to a Chinese school for her primary education and mainstream school for her secondary education. Key is fluent in Mandarin (reading, writing, and speaking) and average in Malay (reading non-complex texts, writing basic Malay, and speaking basic Malay). The Malay language uses Roman alphabets. Key has no problem writing (copying) texts that use the Roman alphabet, but struggles when reading English texts. English was taught as a second language in the Malaysian school system but the language was not used extensively by the students when outside of the classroom. Key explains that she was too embarrassed to speak English because of her fear of making mistakes and being called a "snob".

Since moving to Australia, Key has a different perspective of the English language and appreciates how important and useful it is in Australia. Since joining the conversational English program at the community centre, Key has slowly overcome her fears and speaks more in the program. Key plans to work in dressmaking or massage and facial therapy after she obtains her permanent residency visa. Her visa will also permit her to enroll in government-funded English classes.

\section{ROSE (Congo)}

Rose came to Australia under a religious visa with her husband and five children seven years ago. Rose's husband is a pastor at a local church that serves members who are of African background. Rose is active in the Church programs. The languages used for communication include French, Bantu, Kituba, Lingala, and Tshilumba. Rose speaks French, Lingala, and Tshilumba. Rose at- 
tends the conversational English program at the community centre to practice her English, get involved with other programs at the centre, and also meet friends and make new ones.

Even though Rose has lived in Australia for seven years, she still finds it hard to speak with Australians because of the accent. Rose has completed Certificate III in English and Certificate III in Health Service Assistant. Rose has experience working in aged-care but had to stop working for a while. She has been trying to get back to work but has found that jobs in that industry are now scarce and very competitive. Rose plans to further her studies and go into the Children Services industry.

\section{Responses to Learning Vocabulary using the Tablet}

Table 3 provides examples of direct responses given by the six participants and also some observations. This data was collected during the post-MALL interview, that is, after the women had experienced using the tablet to learn vocabulary.

Table 3: Direct responses by participants and observations from post-MALL interview

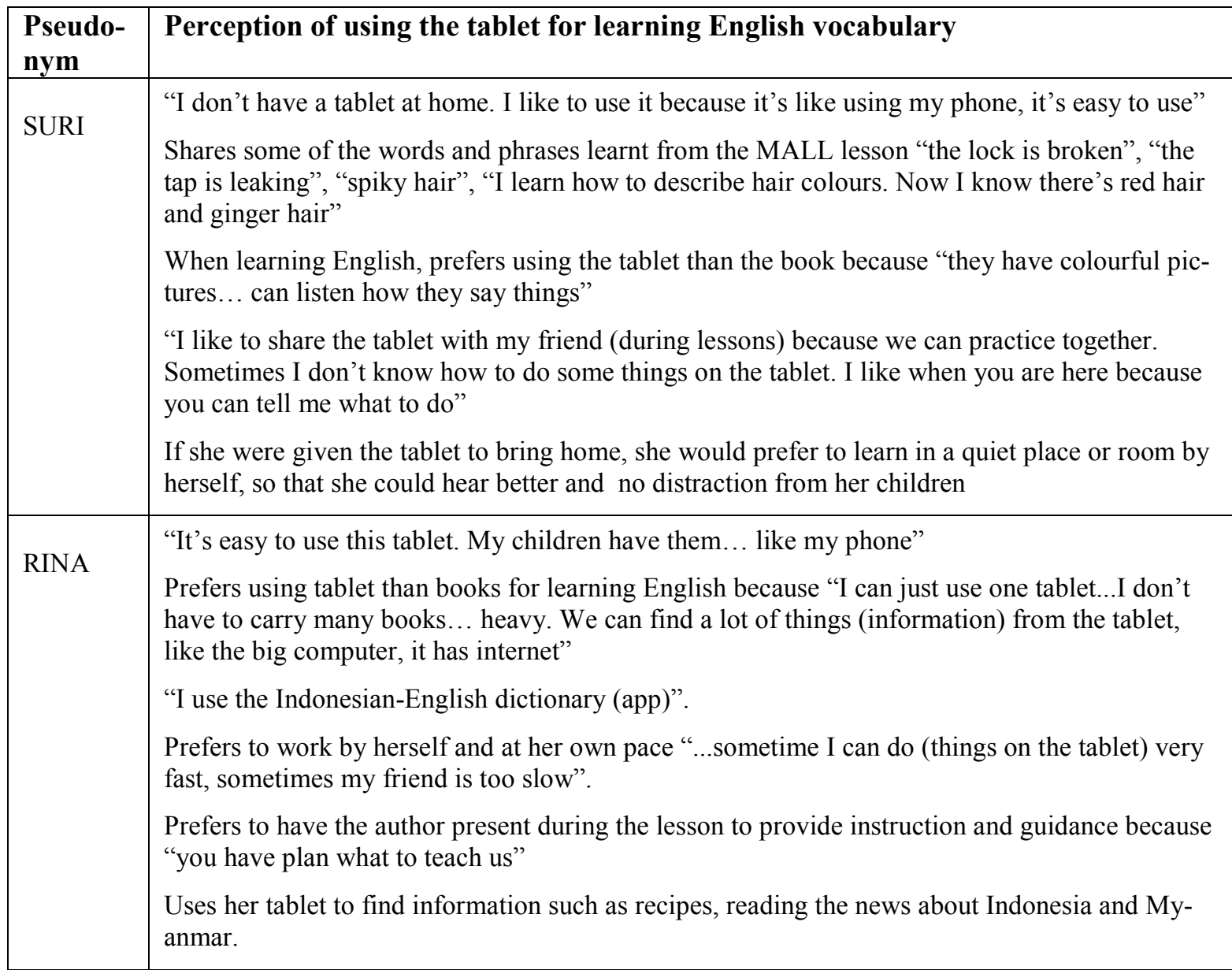




\begin{tabular}{|c|c|}
\hline LIDDY & $\begin{array}{l}\text { Does not own a tablet and considering purchasing one for herself. It is easy to carry compared } \\
\text { to a laptop and she can slip it in her handbag. } \\
\text { Likes to use the tablet because it is easy to use, has similar features like her smartphones, she } \\
\text { can listen to pronunciations and conversations in Australian. } \\
\text { Shares the words/phrases learnt from the MALL lessons - "side burn", "moustache" "spiky } \\
\text { hair" "the toilet's overflowing" } \\
\text { "I sometimes need teacher and sometimes don't. Sometimes I need to ask some questions." } \\
\text { "Sometimes I like to share (the tablet) with my friend, we can discuss...she's funny...(the les- } \\
\text { son) not boring" }\end{array}$ \\
\hline ALLY & $\begin{array}{l}\text { "The tablet is easy to use...the size fit in my bag" } \\
\text { Thinks that the tablet is a good tool for learning English because "it has colour(ful) pic- } \\
\text { tures...can watch movies...can listen to conversation" } \\
\text { Depends on the learning environment, sometimes prefers to learn alone and sometimes with } \\
\text { friends. The advantages of learning with friends are that, they can discuss and practice together. } \\
\text { Shares the words/phrases learnt from the MALL lessons - "menu", "have here or take away?", } \\
\text { "Can I have a coffee, please?", "Can I have a juice, please?", "I'd like", "I'll have" }\end{array}$ \\
\hline KEY & $\begin{array}{l}\text { "I learn more words now" } \\
\text { Likes the size, the pictures and the playing movies features "I like (the) tablet. (It's) easy to use. } \\
\text { I always take it in my bag. I can find information anytime. I can take pictures and videos" } \\
\text { "Sometimes I like to learn by myself, sometimes with friends because it's nice to share" } \\
\text { "I like teacher to teach me... teacher can confirm whether I do things right or not" } \\
\text { Shares the words/phrases learnt from the MALL lessons - "the toilet's overflowing", "the lock } \\
\text { is broken", "she wears glasses" }\end{array}$ \\
\hline ROSE & $\begin{array}{l}\text { "It's easy to use... quite (the) same with my phone. But it's bigger, I can read the bible" } \\
\text { "The tablet (works) like the laptop (computer) but I cannot type letters. I can get Internet...I can } \\
\text { get a lot of information and answers" } \\
\text { Prefers to use the tablet by herself if she's learning French/English, prefers sharing with a friend } \\
\text { and work in small group when doing the MALL lesson. } \\
\text { "I cannot focus so much. I always think about my children" } \\
\text { Shares the words/phrases learnt from the MALL lessons - "The computer is broken", "the tiles } \\
\text { are cracked", "Can I have my receipt, please?", "What would you like today?", "I'll have a cof- } \\
\text { fee, please?" }\end{array}$ \\
\hline
\end{tabular}

\section{Discussion}

Allender (1998) and Hewagodage and O'Neill (2010) maintain that adult learners learning English as a second, third, or fourth language in general, and English vocabulary specifically, are influenced by factors such as level of education in native language (L1), culture, past experiences and knowledge, age, and opportunities to speak English. The results from interviews with the six women in our study reflect this notion clearly, where all six participants are literate in L1 and completed both primary and secondary education. They have experienced formal and structured schooling. Even though they struggle in English, some of their previous learning experience was useful for them. For example, Sri, Rina, and Rosey used the Roman alphabet for L1. They can copy English words or phrases from the board into their personal notebook fairly quickly. Ally 
and Liddy, on the other hand, used Chinese characters to write notes in their native language. Being able to go back to their notes is obviously an advantage for them as this helps them to recall and retain the memory of the words and phrases that they have learnt.

In addition to culture, family and religion play major roles in women's lives (AMES, 2011; ECCV, 2009; McMichael \& Manderson, 2004). The participants, like other women who are of ethnically diverse background, usually can stay out of the house only for a restricted time as they need to, for example, cook lunch, take their baby home for nap time, or simply have to be home by a certain time. These are some of the factors that illustrate how some women, like Suri and Rina, are restricted socially. Furthermore, they are prohibited by the law from finding employment due to the restriction on their visa status, and they are unable to further their education due to financial difficulty. As a consequence, they have fewer opportunities to mix with other Australians, thus leading to isolation from the broader community and taking a longer time than men to overcome language barriers and adjust to life in Australia (Colic-Peisker \& Tilbury, 2007; Fozdar \& Hartley, 2012).

Although all six participants have lived in Australia between 2 to 7 years, they still feel uncomfortable speaking English with native English Australian speakers. They identify that they need to improve their speaking skills to a level of English proficiency that allows them to communicate comfortably. Key, Suri, and Ally had a common concern of feeling embarrassed to speak English outside the program because of their fear of making mistakes. They all have slowly overcome these feelings and each week they are speaking more within the group. Rina, Rose, and Liddy did not have these issues. They had a positive attitude that they could do better and wanted to advance to being able to seek employment. However, they faced a different kind of fear; that is, not feeling ready. They plan to go on to the next step after they have improved their speaking, writing, reading, and listening skills.

All six women expressed concerns of having difficulty understanding the Australian accent. This may be the factor that is causing their fears since it is a problem that they consistently encounter and it becomes a challenge for them. The Office of Multicultural Interests (OMI, 2012) recognizes that, alongside learning and adapting to a new culture, and dealing with emotional, psychological, sociocultural, and socioeconomic challenges, learning English is one of the challenges faced by migrants settling in Australia. The community centre plays a significant role in the lives of the participants. As reported by K.S. Ahmad et al. (2013) and RCOA (2010), the programs offered by such centres provide an alternative to the formal government-funded programs by providing the opportunity and space in a friendly and non-rigid learning environment.

The MALL lessons undertaken by the participants follow three steps: Step 1 - pre-teaching of vocabulary and phrases; Step 2 - drilling to help attendees practice fluency and become familiar with how the words and phrases are used; and Step 3 - completing the exercise using the app downloaded on the tablet. The interactivity and multimedia features of the tablet allow for authentic content (such as a short video of a conversation between two native Australian English speakers) to be presented to participants. The MALL lessons were designed based on the sociocultural approach of Grabinger et al. (2007), Halliday (2004) and Vygotsky (1978), that is, the idea of a social cultural learning environment where learners are exposed to the social norms of and interactions in the target language, and are able to use what they learn for meaningful communication.

The use of the tablet and the MALL learning environment was revealed to have positive effects on participants' vocabulary learning. The apps that were used addressed the topics that were relevant to non-native adult migrant English learners. The contents of the apps were designed in such a way that it gave examples of the Australian culture and language through learning vocabulary. All participants could recall the topics that they had learnt in the MALL lessons and the vocabu- 
laries (words or phrases) that were associated with the topic. The participants demonstrated that they not only acquired the meaning and knowledge of the words and phrases but also were able to use them in the right context.

Some of the words and phrases that participants could recall were:

"the lock is broken", "the tap is leaking", "spiky hair", "side burn", "moustache", "the toilet's overflowing", "Have here or take away?", "Can I have a coffee, please?" "Can I have a juice, please?", "I'd like...", "I'll have...", "Can I have my receipt, please?"

This is a positive indicator, as vocabulary acquisition is important for second language oral proficiency (J. Ahmad, 2011; Choo et al., 2012; Coady \& Huckin, 1997) and the larger the participants' word bank, the more tools they have for processing and communicating their ideas and processing those of others (J. Ahmad, 2011; Elgort, 2011). Kenny (2011), Krashen and Terrell (2000) and Nation and Newton (2009) posit that vocabulary has to be acquired before language acquisition can occur.

In learning a second (or third or fourth) language in a sociocultural learning setting, it is important that cross-cultural understanding and intercultural literacy is embraced by teachers/instructors and learners (Burgoyne \& Hull, 2007; O’Neill \& Gish, 2008). As the facilitator of the group, the author uses MALL lessons that reflect authenticity and suitability for participants of diverse cultures and backgrounds. She also encourages group work and considers Knowles' (1984) principles of andragogy. As noted by Burgoyne and Hull (2007), O'Byrne, (2003) and Martin and Rose (2005), it is essential for participants to engage with each other in coconstructing the knowledge, in this case, the knowledge of the English language. As such, in Step 1 and Step 3, participants were paired to work on tasks and exercises. Participants responded positively about working with a partner when doing the MALL lessons as it allowed them to discuss and practice together.

Depending on their level of English proficiency, familiarity and confidence in using the tablet, and the level of complexity of the topics presented in the MALL lessons, some level of teacher/instructor presence and support is necessary. Participants felt safe when the teacher/instructor was present because she could provide instruction and guidance and provide answers to question, for example, questions about vocabulary or how to navigate the app on the tablet.

The MALL learning environment enriched and provided positive vocabulary learning experiences to the six participants. The tablet, as the mobile device for MALL, has the features that make this possible. These features are connectivity, context sensitivity, portability, individuality, and social interactivity (Klopfer et al., 2002).

Connectivity refers to the ease of connecting the tablet to the internet for access to learning material. In this study, the app was downloaded using the Wi-Fi connection available at the community centre. The internet was used by participants to search for information, such as translation of an English word to their native language.

Context sensitivity refers to the context awareness of the app with user's interaction. For example, in the vocabulary exercise, participants interact with the app interface by tapping, dragging, or swiping their finger/fingers on a button or a bar. The app is designed for easy navigation for beginner English learners. The participants are also alerted, by highlights or blinking cues and prompts, for correct or incorrect answers. Alerts are also shown when participants have completed an exercise and are supposed to move on to the next level. Participants, whether already familiar with using a tablet or not, all commented that this feature made the apps easy to use and navigate. Moreover, the usage is similar to their smartphones, only the tablet has larger screen. Liddy 
thought that it was easy to use the tablet because it had similar features as her smartphone. Rina said "It's easy to use this tablet. My children have them... like my phone."

Portability is a feature of the tablet that provides convenience of use for participants. The tablet has the dimensions of 200x130x13mm and 340g in weight. It is small and can fit into a medium size handbag. Portability also refers to how both the user and the tablet is portable and that the tablet can be used online and offline. The app that is used for the MALL lesson was downloaded onto the tablet, thus learning can take place without constraint, anytime and anywhere, provided the tablet has battery life available. A participant, Key, owns an iPad and likes the convenience of use and the capabilities of the tablet: "I like [the] tablet. [It's] easy to use. I always take it [my iPad] in my bag. I can find information anytime. I can take pictures and videos". Rina does not own a tablet, but she prefers using a tablet than books for learning English because "I can just use one tablet... I don't have to carry many books... heavy. We can find a lot of things [information] from the tablet, like the big computer, it has internet".

The Individuality and social interactivity features of the tablet refer to personalized or customized learning that the participants can choose. Participants can learn vocabulary at their own pace, repeat the lesson, replay audio or video, pause, go back, forward or skip some parts of the app. Participants have a choice of using the tablet individually and personalizing their learning, or learning collaboratively with other participants (Cavus \& Ibrahim, 2009). The multimedia capability of the tablet is also an appealing factor. Liddy said that she can use the app on the tablet to listen to conversations and learn pronunciations in Australian. Ally thinks that the tablet is a good tool for learning English because "it has colour[ful] pictures ... can watch movies ... can listen to conversation". Suri prefers using the tablet than a book when learning English, because "they have colourful pictures ... can listen how they say things". The app included other element for learning vocabulary including flashcards, audio, video, digital worksheet, pronunciations practices, and conversations in Australian accents with accompanying transcript.

\section{Conclusions}

This paper reported the positive effects in six migrant women's vocabulary learning after undertaking a series of MALL integrated vocabulary lessons in a non-formal learning environment. The participants have lived in Australia between two to seven years, but still struggle with English. The study was undertaken at a small community centre in Western Australia that has a 2hour weekly program for people who are non-native English speakers to practice conversational English. The study demonstrated that it is feasible to utilize MALL for migrant women to learn vocabulary, in a non-formal environment, provided the design of the MALL lessons are based on the sociocultural theory of language learning. The sociocultural approach requires a teacher/facilitator to ensure that the learning material delivered to learners is authentic and essential to the learners' needs. The learners should be given the opportunity to collaborate, engage, and interact with their peers in co-constructing meaning and knowledge. The learners should also be able to use what they have learnt and able to communicate it meaningfully. The naturalistic and non-formal feel of the learning environment should be maintained, even with the insertion of the tablet as a learning device.

Migrant women's vocabulary acquisition is affected by both their personal and sociocultural backgrounds that include culture, family responsibility, religion, education background, literacy in L1, past experiences and knowledge, age, and opportunities to speak English. Having some level of literacy in L1 is advantageous for Step 1 of the MALL lesson. Step 2 would benefit all learners. Including MALL in language learning enriches learners' vocabulary learning experiences because of the features of the tablet as a learning device. These features include connectivity, context sensitivity, portability, individuality, and social interactivity. 
This study has provided an understanding of the effects of MALL to migrant women's English language acquisition in general, and vocabulary acquisition in particular. It can be concluded from the discussion that the participants were satisfied with the MALL lessons, had an expanded word bank, and enjoyed the enriched vocabulary learning experience.

Other potential benefits to participants of this study include increased vocabulary skills that lead to confidence in communication thus increasing the participants' potential of becoming socially inclusive within the Australian society. Participants will become capable of taking responsibility of their own learning, possibly using their own mobile device, thus leading to lifelong learning. Familiarity with the mobile devices will increase digital literacy levels as well as facilitate access to useful websites and networks (social, government, or career), thus reducing isolation in participants' lives. These benefits will eventually lead to increased opportunities for employment.

A limitation of the study is the relatively small sample size. As indicated before, this study is part of a larger research project with a larger cohort of participants. Despite the small sample discussed in this paper, these findings provide insight into the broader community of migrant women English learners.

\section{References}

Ahmad, J. (2011). Intentional vs incidental and vocabulary learning. Interdisciplinary Journal of Contemporary Research in Business, 3(5), 67-75.

Ahmad, K. S., Armarego, J., \& Sudweeks, F. (2013, November). Literature review on the feasibility of mobile-assisted language learning (MALL) in developing vocabulary skills among non-English speaking migrant and refugee women. Paper presented at the International Conference on Research and Innovation in Information Systems (ICRIIS), Kuala Lumpur, Malaysia.

Alemi, M., Sarab, M., \& Lari, Z. (2012). Successful learning of academic word list via MALL: Mobile Assisted Language Learning. International Education Studies, 5(6), 99-109.

Allender, S. C. (1998). Adult ESL learners with special needs: Learning from the Australian perspective. Center for Adult English Language Acquisition.

AMES. (2011). Words to work: The experiences of people in the Adult Migrant English Program in Melbourne. Melbourne, Victoria: AMES (Adult Multicultural Education Services) Research and Policy Unit.

ASIB. (2012). Social Inclusion in Australia: How Australia is faring. Australian Social Inclusion Board Retrieved from http://www.socialinclusion.gov.au/sites/www.socialinclusion.gov.au/files/publications/pdf/HAIF_repo rt final.pdf

Billet, S. (1998). Appropriation and ontogeny: Identifying compatibility between cognitive and sociocultural contributions to adult learning and development. International Journal of Lifelong Education, 17, 21-34.

Bimrose, J., \& McNair, S. (2011). Career support for migrants: Transformation or adaptation? Journal of Vocational Behavior, 78(3), 325-333. doi: http://dx.doi.org/10.1016/j.jvb.2011.03.012

Burgoyne, U., \& Hull, O. (2007). Classroom management strategies to address the needs of Sudanese refugee learners: Advice to teachers - Support document: Methodology and literature review. Australian Government.

Burns, R. B. (1994). Research methods. Melbourne: Longman Cheshire.

Burston, J. (2014). Twenty years of MALL project implementation: A meta-analysis of learning outcomes. ReCALL, FirstView, 1-17. doi: 10.1017/S0958344014000159 
Cavus, N., \& Ibrahim, D. (2009). m-Learning: An experiment in using SMS to support learning new English language words. British Journal of Educational Technology, 40(1), 78-91. doi: 10.1111/j.1467-8535.2007.00801.x

Choo, L. E. E. B., Lin, D. T. A. N. A, \& Pandian, A. (2012). Language learning approaches: A review of research on explicit and implicit learning in vocabulary acquisition. Procedia - Social and Behavioral Sciences, 55(0), 852-860. doi: http://dx.doi.org/10.1016/j.sbspro.2012.09.572

Chuang, K. W. (2009). Mobile technologies enhance the E-learning opportunity. American Journal of Business Education, 2(9).

Coady, J., \& Huckin, T. (1997). Second language vocabulary acquisition: A rationale for pedagogy. Cambridge: Cambridge University Press.

Coates, K. M., \& Carr, S. C. (2005). Skilled immigrants and selection bias: A theorybased field study from New Zealand. International Journal of Intercultural Relations, 29(5), 577-599.

Colic-Peisker, V., \& Tilbury, F. (2007). Refugees and employment: The effect of visible difference on discrimination. Murdoch University: Perth, WA.

Creswell, J. W. (2012). Educational research: Planning, conducting, and evaluating quantitative and qualitative research (4th Ed.). Boston: Pearson.

ECCV. (2009). Social inclusion for migrants and refugees. Statewide Resources Centre: Carlton, Victoria.

Elgort, I. (2011). Deliberate learning and vocabulary acquisition in a second language. Language Learning, 61(2), 367-413. doi: 10.1111/j.1467-9922.2010.00613.x

Fozdar, F., \& Hartley, L. (2012). Refugees in Western Australia: Settlement and integration. Metropolitan Migrant Resource Centre Inc.

Grabinger, R. S., Aplin, C., \& Ponnappa-Brenner, G. (2007). Instructional design for sociocultural learning environments. E-Journal of Instructional Science and Technology, 10(1).

Gu, X., Gu, F., \& Laffey, J. M. (2011). Designing a mobile system for lifelong learning on the move. Journal of Computer Assisted Learning, 27(3), 204-215. doi: 10.1111/j.1365-2729.2010.00391.x

Halliday, M. A. K. (2004). An introduction to functional grammar. London: Hodder Arnold.

Hewagodage, V., \& O'Neill, S. (2010). A case study of isolated NESB adult migrant women's experience learning English: A sociocultural approach to decoding household texts. International Journal of Pedagogies \& Learning, 6(1), 23-40.

Klopfer, E., Squire, K. \& Jenkins, H. (2002). Environmental detectives: PDAs as a window into a virtual simulated world. In Proceedings of IEEE International Workshop on Wireless and Mobile Technologies in Education. IEEE Computer Society, Vaxjo, Sweden, pp. 95-98.

Kenny, L. A. (2011). Doing students justice: How first language acquisition influences second language acquisition. Illinois Reading Council Journal, 39(4), 10-14.

Knowles, M. S. (1984). Andragogy in action: Applying modern principles of adult education. San Francisco: Jossey Bass.

Krashen, S. D., \& Terrell, T. D. (2000). The natural approach: Language acquisition in the classroom. London: Prentice Hall.

Kunz, E. F. (1973). The refugee flight: Kinetic models and forms of displacement. International Migration Review, 7(2), 125-146.

Leedy, P. D., \& Ormrod, J. E. (2005). Practical research: Planning and design (8th Ed.). Upper Saddle River, NJ: Prentice Hall.

Lightbown, P. M., \& Spada, N. (1993). How languages are learned. Oxford: Oxford University Press.

Martin, J. R., \& Rose, D. (2005). Designing literacy pedagogy: Scaffolding asymmetries. London: Equinox. 
McDonough, J., \& McDonough, S. (1997). Research methods for English language teachers. London: Arnold.

McMichael, C., \& Manderson, L. (2004). Somali women and well-being: Social networks and social capital among immigrant women in Australia. Human Organization, 63(1), 88-99.

Migliorino, P. (2011). Digital technologies can unite but also divide: CALD communities in the digital age. Aplis, 24(3).

Miralles-Lombardo, B., Miralles, J., \& Golding, B. (2008). Creating learning spaces for refugees: The role of multicultural organisations in Australia.

Mishra, S. (2010). Researching mobile learning - By Giasemi Vavoula et al. British Journal of Educational Technology, 41(2), E37-E38. doi: 10.1111/j.1467-8535.2010.01060_14.x

Nation, I. S. P., \& Newton, J. (2009). Teaching ESL/EFL listening and speaking. New York: Routledge.

O’Byrne, B. (2003). The paradox of cross-age multicultural collaboration. Journal of Adolescent and Adult Literacy, 47(1), 50-63.

O’Neill, S., \& Gish, A. (2008). Teaching English as a second language. South Melbourne: Oxford University Press.

OMI. (2012). New and emerging communities in Western Australia. Government of Western Australia, Office of Multicultural Interests.

Ozdogan, M., Basoglu, N., \& Ercetin, G. (2012, July). Exploring major determinants of mobile learning adoption. Paper presented at the PICMET Conference: Technology Management for Emerging Technologies, Vancouver, Canada.

Qian, D. D. (1999). Assessing the roles of depth and breadth of vocabulary knowledge in reading comprehension. Canadian Modern Language Journal, 56, 262-305.

RCOA. (2010). What works: Employment strategies for refugee and humanitarian entrants. Surry Hills, NSW: Refugee Council of Australia (RCOA).

Smith, M. K. (2002). Malcolm Knowles, informal adult education, self-direction and andragogy. The Encyclopedia of Informal Education. Retrieved from www.infed.org/thinkers/et-knowl.htm

Smolicz, J., \& Secombe, M. J. (2003). Assimilation or pluralism? Changing policies for minority languages education in Australia. Language Policy, 2, 3-25.

Stockwell, G., \& Hubbard, P. (2013). Some emerging principles for mobile-assisted language learning. The International Research Foundation for English Language Education.

Tai, Y. (2012). Contextualizing a MALL: Practice design and evaluation. Educational Technology \& Society, 15(2), 220-230.

Thomson, S., \& De Bortoli, L. (2012). Preparing Australian students for the digital world: Results from the PISA 2009 Digital Reading Literacy Assessment. Retrieved from http://www.acer.edu.au/documents/PISA2009_PreparingAustralianStudentsForTheDigitalWorld.pdf

Thornton, P., \& Houser, C. (2005). Using mobile phones in English education in Japan. Journal of Computer Assisted Learning, 21(3), 217-228. doi: 10.1111/j.1365-2729.2005.00129.x

UN. (2013). Refugees - Overview of forced displacement. Resources for Speakers on Global Issues. Retrieved from http://www.un.org/en/globalissues/briefingpapers/refugees/overviewofforceddisplacement.html

UNHCR. (2011). UNHCR resettlement handbook. UN Refugee Agency:

Viberg, O., \& Gronlund, A. (2012, October). Mobile Assisted Language Learning: A literature review. Paper presented at the 11th International Conference on Mobile and Contextual Learning, Helsinki, Finland. 
Vygotsky, L. (1978). Mind in society: The development of higher psychological processes. Cambridge, MA: Harvard University Press.

Ward, C., Bochner, S., \& Furnham, A. (2001). The psychology of culture shock. (2nd ed.). Routledge: Hove.

Wu, W. H., Wu, Y. C. J., Chen, C. Y., Kao, H. Y., Lin, C. H., \& Huang, S. H (2012). Review of trends from mobile learning studies: A meta-analysis. Computers \& Education, 59(2), 817-827. doi:

http://dx.doi.org/10.1016/j.compedu.2012.03.016

Yin, R. K. (2011). Qualitative research from start to finish. New York: Guilford Press.

\section{Biographies}

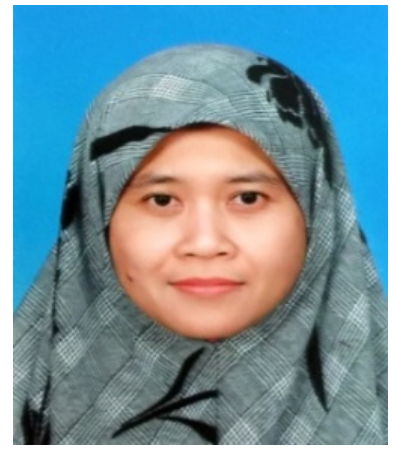

Kham Sila Ahmad is a PhD student in the School of Engineering and IT at Murdoch University, Western Australia. Her research is concerned with the impact of integrating mobile assisted language learning (MALL) into non-native English speaking migrant women's English vocabulary learning, within non-formal learning environment in the Australian context.

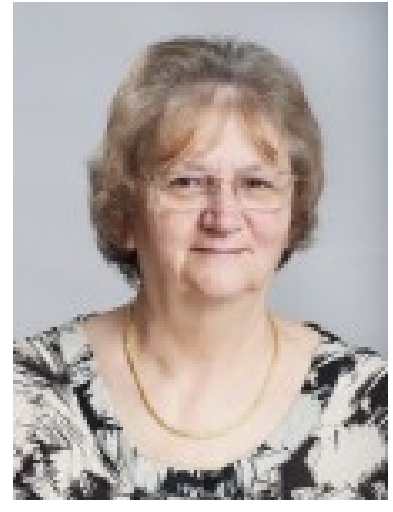

Fay Sudweeks is an Associate Professor Emerita in Information Systems at Murdoch University. She has a PhD in Communication Studies. Her research interests include the impact of technologies on learning, communication, and culture. She is on the editorial board of numerous journals including the Journal of Computer-Mediated Communication, New Media and Society, Human Communication Research, and International Journal of e-Learning. She has co-chaired the international and interdisciplinary conference series on Cultural Attitudes towards Technology and Communication.

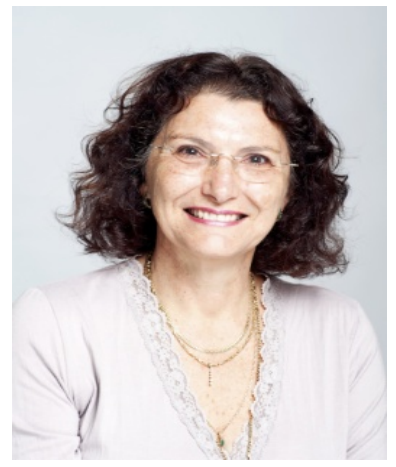

Jocelyn Armarego is a Senior Lecturer in the School of Engineering and IT at Murdoch University, Western Australia. Her PhD involved how learning differs from professional practice in engineering. Her research interests include education for ICT-based disciplines, women in non-traditional areas and the cultural aspects of information systems. 